Res Publica. Revista de Historia de las Ideas Políticas ISSN-e: 1989-6115

\title{
La extimidad del adversario político. Guerrilla mítica y contención psicológica de la radicalidad política
}

\author{
Edgar M. Juárez-Salazar*; Hans R. Saettele Zuend**
}

Recibido: 21 de mayo de 2018 / Aceptado: 14 de diciembre 2018

Resumen. El presente trabajo analítico busca posicionar la noción lacaniana de extimidad como un elemento constitutivo y sustancial de la identidad política del guerrillero como adversario político problematizando su potencial exterioridad en el plano psicosocial. Situación que se presenta, desde nuestra postura lacaniana, en contraposición de diversos reduccionismos psicológicos que limitan y constriñen los efectos subversivos de los disidentes a un régimen de Estado y que son interpretados generalmente por la psicología social mainstream. Ulteriormente, se pretende vincular la idea de guerrillero a una conceptualización mítica por la cual éste puede ser descrito, y que permite manejar y disipar la contingencia subversiva, de una manera más sutil, desde la estructuración mítica de su identidad buscando controlar su incidencia en un sistema político.

Palabras clave: adversario político; exterioridad; extimidad; guerrilla; radicalidad.

\section{[en] The Extimacy of Political Adversary. Mythical Guerrilla and Psychological Containment of Political Radicalism}

\begin{abstract}
This paper seeks to link the lacanian concept of extimacy with the political identity of partisan as political adversary problematizing his potential exteriority in the psyhcosocial plane. On the one hand, in this problem, from our lacanian position, arises an opposition with the mainstream psychological concepts about the partisan and his actions and effects in the ground of state political exchanges interpreted by social psychology. Later, we will point out the linkage between the partisan concept and the mytical reference of this one. The partisan myth tries to disolve the subversive contingency, in a more subtle way, from the same mythical structure is intended to control the incidence of this one in the political system.
\end{abstract}

Keywords: Political adversary; Exteriority; Extimacy; Guerrilla; Radicalism.

Sumario: 1. Introducción. 2. Extimidad y conciencia psicologizada del guerrillero como adversario. 3. El guerrillero como mito. 4. Conclusiones

Cómo citar: Juárez-Salazar, E. M.; Saettele Zuend, H. R. (2019). La extimidad del adversario político. Guerrilla mítica y contención psicológica de la radicalidad política, en Res Publica 22.1, 247-258

\footnotetext{
* Universidad Autónoma Metropolitana Xochimilco México ejuarez@correo.xoc.uam.mx

** Universidad Autónoma Metropolitana Xochimilco México hrzuend@correo.xoc.uam.mx
} 


\section{Introducción}

En la primera línea de la novela más emblemática de Gabriel García Márquez, Cien años de soledad, se lee un fragmento brutal que vale, quizás, la relevancia histórica y referencial de toda la novela: "Muchos años después, frente al pelotón de fusilamiento, el coronel Aureliano Buendía había de recordar aquella tarde remota en que su padre lo llevó a conocer el hielo". Ese pequeño extracto, tan citado y tan analizado por los críticos literarios no hace sino mostrarnos lo absurdo de lo cotidiano, la extrañeza, lo ajeno pero, a su vez, lo íntimo, lo interior que circunda la vida exterior de un General y su legendario pueblo donde todo lo nuevo se convierte en parte de una cotidianidad extraña pero a la vez íntima, exuberante, ajena, increíble y legítima; el lugar donde incluso algo tan común como el hielo resulta insólito y desconocido.

Este breve pasaje se convierte en algo aún más punzante cuando, ese Macondo no deja de representar, cada vez de forma más aguda, a muchos de los pueblos latinoamericanos con sus añejas dictaduras, sus subversiones guerrilleras y sus movilizaciones políticas, con sus persecuciones, sus desaparecidos y sus estériles mártires políticos oficiales. Para pensar aquí en la noción de guerrillero no dejamos de focalizarla en América Latina y las represiones de la que los militantes de diversos grupos fueron presa. Este periplo es necesario para comenzar a describir un tema que plantea una relación entre uno de los conceptos más limítrofes de la teoría lacaniana pero, sustancialmente necesario, para pensar la política contemporánea; se trata de un extraño concepto en sí mismo en psicoanálisis y también en su relación con la vida política de los sujetos. Nos referimos al término extimidad, que es aludido mayoritariamente en el ámbito clínico del psicoanálisis, pero que muestra de forma clara su funcionalidad para cuestionar y reflexionar lo político.

En el presente trabajo se busca pues amalgamar la noción lacaniana de extimidad a la lógica política y denunciar cierta reducción de la identidad política del guerrillero realizada desde el ámbito de la psicología social positiva pretendidamente neutral en su política. Nos referimos a esa psicología social que produce un estándar y rellena anaqueles cada vez más abultados de clasificaciones, que busca categorizar lo diferente, lo ajeno, lo subversivo. Con lo anterior, pretendemos elucidar la fuerza psicológica que pretende aniquilar la potencia radical del acontecimiento disidente con el afán de producir un saber ideologizado sobre los militantes guerrilleros y esto es posible a través del uso subversivo que le otorgamos a la teoría psicoanalítica lacaniana. En un primer momento explicitaremos la relación entre extimidad y la conciencia como creadora de significaciones imaginarias sobre el guerrillero como adversario para dar paso a un segundo momento donde proponemos pensar al guerrillero como mito organizador de la clasificación psicológica.

Sabemos también que no es posible reducir todos los modos de guerrilla a una conceptualización unívoca pues son muy vastos los matices estructurales, afinidades políticas, momentos históricos y situaciones afines a la diversidad guerrillera en todas las latitudes de la realidad latinoamericana y mundial. Entendemos aquí, de manera general, al guerrillero como aquel que combate de manera frontal a un Estado y de forma particular como alguien que alude ciertas características y posicionamientos políticos que se sostienen al interior de una guerra entre lo legítimo y lo ilegítimo, combate que se encuadra en un contexto revolucionario generalmente armado.

G. García Márquez, Cien años de soledad, Colombia, Alfaguara, 2007, p. 9. 
Siguiendo el concepto de partisano de Carl Schmitt, el cual se ha traducido al castellano como guerrillero, podemos sugerir que se trata de alguien que "combate de forma irregular" pero que, paralelamente, "goza de ciertos derechos regulares" en una dinámica político-estatal determinada ${ }^{2}$. La lucha guerrillera tiene, por lo general, justamente ese matiz paradójico entre lo que, en su misma irregularidad, puede ser interpretado y juzgado, despreciado o valorizado, se trata pues, en líneas generales, de la encrucijada de la enunciación de la guerrilla por parte del Estado, los medios de comunicación y del sentido común.

\section{Extimidad y conciencia psicologizada del guerrillero como adversario}

El término extimidad es un neologismo del psicoanalista francés Jacques Lacan que resulta de vital importancia para pensar las operaciones de estructuración identitaria sobre el adversario político. Con base en las elaboraciones teóricas desarrolladas por Lacan en torno a la construcción de la realidad humana a partir de los registros imaginario, simbólico y real; el término extimidad parece convertirse en un elemento central para la configuración misma del sujeto, pues se encuentra, por decirlo de cierta manera, en el núcleo de la edificación simbólica estructural de éste. Aunque no se trata de un concepto central en la enseñanza de Lacan, su rastreo y potencialidad son importantes para nuestra reflexión.

Según Lacan, la "extimidad" se presenta, de forma general, como una "exterioridad íntima" que se encuentra dispuesta en el "ángulo" de la "cosa"3. La cosa, extraída por Lacan del término empleado aleatoriamente por Freud ${ }^{4} 5$ a lo largo de su obra, permite introducir un acercamiento al orden de lo real y a la función estructurante del sistema simbólico. Por su parte, el término extimidad en Lacan, va a referir también cierta representación interna de lo innombrable del deseo del sujeto, su resquicio más incesante que, por ser tan próximo a lo real, no cesa de no escribirse y constituye, a su vez, un lugar intimamente ajeno que le concede, inherentemente, una característica siniestra u ominosa.

La condición de representación esgrimida por Lacan para acudir a la utilización del concepto de Cosa (das Ding) se afina aún más al situarse de manera similar a la cosa en sí elucidada por Kant para quien representa "una cosa que ha de ser pensada como cosa en sí misma, y no como objeto de los sentidos" que "limita", a su vez, "la validez objetiva del conocimiento sensible" y no puede "aplicarse a todo cuanto el entendimiento piensa". Precisamente, la cosa en sí, toma distancia de los "fenómenos" y al situarse fuera de su "campo" se presenta como "vacío". La condición de vacío manifiesta aquello que señala el "límite" que frunce las "pretensiones de la sensibilidad". El límite entre fenómeno y la cosa en sí describe cierta incapacidad de contener todo el entendimiento sensible del mundo; sin embargo, como vacío, precisa una posibilidad de conocimiento del mundo objetal capturado en las demar-

\footnotetext{
C. Schmitt, Theory of the partisan, New York, Telos Press Publishing, 2007, p. 23.

J. Lacan, El Seminario Libro VII La ética del psicoanálisis, Buenos Aires, Paidós, 2009, pp. 171-172.

S. Freud, "La negación”, en S. Freud, Obras Completas Vol. XIX, Buenos Aires, Amorrortu, 1992, pp. 248-249.

S. Freud, "Proyecto de Psicología". en S. Freud, Obras Completas Vol. I, Buenos Aires, Amorrortu, 1992, pp. 323-446.

6 I. Kant, Crítica de la razón pura, Madrid, Gredos, 2010, pp. 251-252.
} 
caciones internas que presentan la imposibilidad de capturar al fenómeno completamente.

Ahora bien, para Lacan existe una relación concreta entre lo íntimo y lo exterior que puede ser entendida a partir de la triada entre objeto a, la cosa y la extimidad. Estos tres elementos tienen en común su dependencia con lo real fundamentalmente, y también con lo imaginario y lo simbólico. En un momento ulterior al seminario de 1959-1960, Lacan aproxima una nueva articulación del el objeto $a$, entendido aquí como objeto causa del deseo, aquello que "cosquillea en el interior de la das Ding". Trastocándose en su multiformidad y capturado en la "vacuola del goce". Es así como el objeto a no deja de presentarse al interior de las representaciones-cosa del mundo articuladas por el sujeto ${ }^{7}$. Su relación con la Cosa no es sino la objetivación de aquello que carece de una representación-articulación unitariamente simbólica pues la Cosa se sitúa en el orden de lo real.

En esta conjunción entre el objeto a y la Cosa, la extimidad juega un papel trascendente pues en ella reside cierta cimentación íntima que es llevada a cabo por el sujeto y reproducida incesantemente por éste. En palabras de Pavón-Cuéllar, "la Cosa va extimándose en la medida en que se constituye la experiencia íntima del sujeto que otorga significado y existencia a las cosas externas del sujeto"; situación que produce un "interior personal" que otorga "origen y horizonte al exterior impersonal" para definir lo interior "subjetivo" como "finitud" del "entorno objetivo",

En este sentido, la esencia de la extimidad recae en su necesaria e imprescindible relación con el Otro, es decir, con el sistema simbólico de la cultura. Es allí, en el tesoro barrado de los significantes donde se constriñe y configura una parte de la realidad internalizada del sujeto. En este sentido, según Jacques-Alain Miller, "la extimidad del sujeto es el Otro" y de esta forma "la extimidad está atada a la vacilación de la identidad el sujeto mismo". En otras palabras, es mediante el zarpazo de la extimidad en la constitución del sujeto que éste no sólo fija su relación íntima con lo externo sino configura también su identidad política puesto que ésta se encuentra matizada en el horizonte de lo inconsciente que es, necesariamente, exterior. Sin embargo, es en la representación internalizada del mundo exterior donde tiene cabida y amplitud la identidad política; la cual sostiene, de entrada, una multiplicidad que remite al sentido, a la adecuación imaginaria de esta identidad producida simbólicamente desde el Otro, una intersección de los registros en conjunto con el vórtice de lo real de la Cosa.

La cuestión se torna más aguda cuando, en palabras de Miller, "el sujeto, en el sentido de Lacan" es, en sí mismo, "el lugar de la extimidad"10. Pues según el mismo Miller, "es la imagen del Otro la que define el interior, el sentimiento del interior, el sentimiento de su intimidad". Este punto precisa que la extimidad exhibe la "carencia de una complementariedad", la ausencia de un "ajuste entre el adentro y el afuera, y que hay precisamente un afuera en el interior" 11 . Lo anterior sostendría una

J. Lacan, El Seminario Libro XVI De un Otro al otro, Buenos Aires, Paidós, 1968, p. 213.

8 D. Pavón-Cuéllar, "Extimacy”, en T. Teo (ed.) Encyclopedia of Critical Psychology, New York, Springer, 2014, pp. 661-664, aquí p. 662.

9 J. A. Miller, "Extimité”, en M. Bracher, M. Alcorn, R. J. Corthell y F. Massardier-Kenney, Lacanian Theory of Discourse Subject, Structure, and Society, New York, New York University Press, 1994, pp. 74-87, aquí p. 77.

10 J. A. Miller, Extimidad, Buenos Aires, Paidos, 2010, p. 29.

11 Ibidem, p. 31. 
tesis innegable sobre el inconsciente como lo político, eminentemente exterior y constitutivo del sujeto, desde la creación imaginaria de una identidad interior.

Es así como lo consciente, como cualidad íntima mediante la cual podemos contener el mundo exterior, no es sino una adecuación imaginaria de la forma en que se conoce la realidad material. Siguiendo a Parménides en su respuesta dialéctica a Sócrates, "las formas" no "tienen el poder que tienen respecto de las cosas de entre nosotros, ni las cosas de entre nosotros respecto de aquellas, sino que unas y otras lo tienen respecto de sí mismas"12. Esto plantea que existe una imposibilidad de conocer aquellas ideas -formas- si no es a través de su relación en sí misma fragmentada y en su fuerza propiamente incognoscible pero fundamentalmente relacional.

Huelga decir que el concepto de extimidad tiene también su sostenimiento en las lógicas que matizan la realidad política de los sujetos, a saber entre lo público y lo privado como dos momentos de toda construcción social. Para precisar ese espacio de extimidad, Tisseron, más allegado a un pensamiento centrado en la imagen, refiere que se trata de los "procesos por los cuales unos fragmentos del sí mismo íntimo son propuestos a la mirada de la otredad con el fin de ser validados"13 y que, sin embargo, cuando están referidos al otro semejante no dejan de posicionarse en un registro imaginario. Esta exposición es la que formaliza que lo íntimo se encuentra en un endeble vínculo con lo público y lo privado y, para decirlo de manera más exacta, constituyen un núcleo indescifrable a plenitud desde su condición ontológica pero no en su funcionalidad social. En otras palabras, si lo íntimo existe, es precisamente porque necesita del sistema simbólico de la cultura para subsistir, para tener fundamento de existencia; es el inconsciente que opera desde lo exterior lo que permite la articulación de lo político y que bordea lo real innombrable.

El surgimiento de la extimidad como factor político resulta evidente cuando nos proponemos indagar en sus efectos a nivel de las relaciones vinculares entre sujetos a través de una economía de sus discursos. El primero de estos efectos, quizás el más siniestro, sea la segregación. La clausura sobre el deseo y el robo del goce como garante de una identidad absoluta que produce excluir lo otro, a lo diferente, a lo ajeno. Si bien estamos situados en el universo simbólico de la cultura donde se realizan los cimientos de la edificación social, la pesada loza de lo imaginario y sus identidades en busca de un absoluto no dejan de buscar reorganizar el sistema político y el mismo sistema simbólico a través de los significantes y la delimitación imaginaria de las identidades políticas mediante los significados.

En otras palabras, ya no solamente hablamos de una relación entre el sujeto y el otro semejante sino incluimos también al sistema simbólico, al tesoro oscuro de los significantes quien precisa también el lugar de lo diferente que sigue siendo una parte propia del sujeto mismo aún siendo extraño y amenazante. La Cosa en sí misma, va a señalar Lacan, es el "extranjero, incluso hostil", la "primera exterioridad"14. La relación imaginaria entre el sujeto y su otro semejante es, como hemos mencionado, simplemente un vínculo social a nivel de lo imaginario con impasses en lo real y lo simbólico. Así mismo, el imaginario y lo real son expresados a partir del goce que se solidifica en la noción de sociedad e incluso de comunidad, permite segregar a lo diferente, a las prácticas no normadas en el imaginario y de esta manera poder

Platón, Diálogos, Madrid, Gredos, 2014, p. 361.

S. Tisseron, "Intimité et extimité", en Communications, 88, 2011, pp. 83-91, aquí p. 84.

J. Lacan, El Seminario Libro VII La ética del psicoanálisis, op. cit., p. 68. 
contener la emergencia contingente de toda actividad política. Aún sosteniéndose en la ideología, las relaciones sociales prácticas son las que nutren la diferencia como aspecto fundacional de lo íntimo que evita ser puesto en juicio.

Como apunta Gómez, "las comunidades, las fraternidades, están atravesadas por lo real de un goce inadmisible que expulsa lo extraño en el Otro pero al mismo tiempo, en uno mismo"15. Cuando incluimos la figura del Otro como sistema organizador simbólico, y del sujeto como un significante que es representado por la vía de otros significantes, se manifiesta que lo estructural del orden simbólico es lo que introduce el mecanismo de la segregación de lo diferente. Es el Otro en esencia, pero con el trabajo del sujeto que es barrado por el tesoro de los significantes, quien impregna al sujeto del virus de la identidad por vía del lenguaje y su sostén imaginario vehiculizado en los vínculos sociales, en la amenaza que es producida por la diferencia y que es irreductible.

Es entonces la práctica social la que presenta ese elemento discordante que impide la plenitud del goce propio por vía del Otro y el goce de éste mediante la economía discursiva. Si el orden aparentemente común de las res pública se ve amenazado por un elemento disonante es porque en el orden propio, pero a la vez ajeno, existe una potencia de amenaza al goce individual y también a la fantasía ideológica imaginaria que ese goce contiene. Es el mandato omnipotente del goce del Otro, sostenido en la fantasía de completud y en el pretendido saber de la otredad, en el cual el sujeto desconoce, en sí mismo, lo que origina su deseo y la necesidad de aniquilar la diferencia a partir de este deseo incognoscible.

De esta manera, cuando se establece un dominio imaginario en las relaciones sociales no se deja de reproducir la ideología y con esto se fortalecerse de forma organizada la disposición simbólica del sistema; es la práctica en sí la que hace a los sujetos engañarse con el lenguaje. Todo acto de segregación o racista puede pasar por legítimo sin el menor de los problemas gracias a la fantasía ideológica. La sociedad, en sí misma, se reproduce también como una degradación de la cultura que, pese a sus desigualdades, funciona. Eppur si muove de los registros simbólico, real e imaginario. Es en el registro imaginario, como señala Flower MacCannell, donde la "sociedad" concebida como un "comercio de imágenes" tiene una "mayor ventaja" sobre las sociedades que se articulan en el mero "intercambio simbólico" pues en las primeras se desarrolla una "totalidad singular" para devenir en una sociedad que busca "uniformizar" y "clausurar el conflicto"16. Es en este punto donde la extimidad se transforma en el núcleo traumático de la "clausura" del conflicto social pues como parte del anudamiento borromeo su potencia real reinscribe las coordenadas del actuar del sujeto y de la identidad política delimitada por los meros intercambios sociales en lo imaginario.

Hasta este punto, la conceptualización de la extimidad, el goce y la segregación nos permiten presentar la figura del guerrillero como un sujeto amenazante y extimo en el orden político establecido, mediante su propio ejercicio de su goce. Esto es posible porque el sujeto ocupa un lugar práctico en el discurso del Otro, es mediante él que existe un principio de goce pero también un punto limitativo, interno en apa-

M. Gómez, “Segregación. Odiar la manera particular en que el Otro goza”, en Ética y Cine Journal, 3, 2013, pp. 7-9, aquí p. 7.

16 J. Flower MacCannell, "Lacan's Imaginary. A practical guide”, en S. Tomšič y A. Zevnik, Jacques Lacan: between psychoanalysis and politics, London, Routledge, 2016, pp. 72-85, aquí p. 76. 
riencia, pero sustancialmente exterior. Como señala Derek Hook, "el Otro como lenguaje" precisa el "marco" de "inteligibilidad comunicativa" donde "coincide con la erupción dentro de lo cotidiano"17. La indeterminación del lenguaje es el fundamento mismo del Otro y es la referencia que soporta el hacer político y, al mismo tiempo, produce la imposibilidad de escapar del lenguaje mismo pues no hay Otro del Otro. Con esto se vislumbra el horizonte organizativo del sistema simbólico pero también su misma incapacidad de contener el universo de lo real y del ejercicio del goce por cada uno de los sujetos, condición que demuestra la incapacidad misma del lenguaje para decirlo todo.

En este sentido, según Fioretti Katz, "la idea de extimidad señala su presencia según el modelo de un cuerpo extraño que reconoce una ruptura constitutiva de la intimidad" ${ }^{18}$. El agente de extrañeza no sólo es la instancia de lo diferente o lo ajeno, sino también, necesariamente, es una alusión al determinante de la propia constitución pretendidamente individual del sujeto, cuando menos en su relación imaginaria que es establecida en lo imaginario y estructurada après coup por la relación significante al sistema simbólico de la cultura que posiciona le posiciona como agente político de lo inconsciente.

Existe, con esto, una apuesta por la ruptura con lo externo que no cesa de resarcirse cada que se ronda lo real del goce; lo real que insiste para evitar la clausura o para disuadir la finitud de lo simbólico. En este sentido, la extimidad exhibe su relación política al permitir dibujar al adversario, llegando a fijarse como enemigo ${ }^{19}$, al extraño en terreno propio; no sólo en términos de anormalidad sino también porque en la misma distinción de lo otro como diferencia existen rasgos contingentes de la propia posición política de los sujetos. Puntualmente se trata de aquel elemento ajeno pero esencial de la posición política del sujeto en el lenguaje y su ulterior relación política.

Las peripecias entre la extimidad y lo interno, entre lo inteligible y lo sensible, nos llevan a reflexionar sobre la disposición de la ciencia psicológica positiva y neutralizadora que, en cierta medida, internaliza condiciones primordialmente exteriores haciéndolas pasar por el juicio omnipresente de la razón y de la certeza. Su fundamento como ciencia radica precisamente en su capacidad de aglomerar, con intentos de universalismo, para poder determinar y normar toda acción subversiva del sujeto. El guerrillero, al presentarse como alguien que cuestiona el establecimiento de las normas, excusa su inserción en una demanda al saber de ese gran Otro; y también podría decirse que opta por otro goce que va a perturbar el saber absoluto del Otro. Con esto, la posición del sujeto guerrillero, visto desde una óptica de extimidad, es articulada como agente que cuestiona la disposición de la verdad como posibilidad irruptora y no simplemente la acepta como el único horizonte definido y adecuado de su actuar político a pesar de los esfuerzos de clasificación, regulación e interpretación surgidos desde algunas psicologías.

17 D. Hook, "Absolute other: Lacan's «big Other» as adjunct to critical social psychological analysis?" en Social and personality psychology compass, 2008, pp. 1-24, aquí p. 6.

18 L. Fioretti Katz, "Extraterritorialidad y extimidad: el monolingüismo del otro como política de la lengua", en Humanidades. Revista de la Universidad de Montevideo, XII, 2012, pp. 75-97, aquí p. 81.

19 Hemos optado por el término adversario político pues resulta ser el concepto genérico en psicología social y política. No evitamos con esto la referencia clásica de enemigo planteada en C. Schmitt, La notion de politique, Paris, Calmann-Levy, 1972. Sin embargo, creemos que la noción de enemigo refiere más a la oposición y adversario presenta una connotación de resistencia política con un objetivo específico. 
Podemos decir que el sujeto guerrillero, como agente de lo diferente y desafiante, cuestiona la internalización de un lugar en la cadena discursiva, alterando la posición del significante amo o buscando hacerlo titubear. Al cuestionar el orden simbólico imperante y sostenido por un imaginario socializado por los sujetos, el guerrillero no puede ser reducido a una interpretación psicológica interna pues su relevancia surge del mismo cuestionamiento del sentido sobre su disidencia y su lugar en la cadena discursiva. Si el guerrillero cuestiona, incluso sin saberlo, la internalización, es justamente porque puede penetrar en la extimidad del sistema simbólico.

Si la alternativa de la guerrilla incide en la lógica social del sistema político es porque busca quebrantarlo y repite, de forma diferente, desde las prácticas propiamente guerrilleras que "dañarían" a la sociedad y sus constructos del bien común, desvelando la organización social provista y segmentada por el Otro. Factores como el terror en los actos subversivos de los guerrilleros cobran mayor relevancia dado que no sólo se ataca al Estado sino porque se pone en juego el goce entre aquello que es puramente exterioridad organizadora y puede inscribirse en el lugar más íntimo pretendidamente individual y neutral de las formas políticas establecidas mediante el bien común para los sujetos en sociedad.

Paralelamente, existen algunos ejercicios intelectuales propios o afines a la psicología social para indagar en la personalidad y actuar del guerrillero como terrorista clasificado a partir de conductas determinadas en su acción contrasistémica psicológica ${ }^{20}$, mediante una violencia que puede ser determinada mediante factores pretendidamente externos que esbozan su internalización ${ }^{21}$ e incluso que pueden ser fundamentados en las denominadas creencias sociales ${ }^{22}$. Estos estudios dan cuenta de lo estéril que resulta reducir la subversión al sentido común hegemónico y al ejercicio de normalización-categorización supuestamente social y analizadoramente neutral de ciertas instancias de la ciencia psicosociológica.

Estudiar desde la psicología social reduccionista mainstream a los guerrilleros nos lleva a encontrar cómo es posicionado el actuar político disidente mediante una condición de anormalidad, de daño, de extrañeza, de enemistad amenazante y de un adversario necesariamente eliminable. Como si se tratase del núcleo o tumor dañino que hubiera que clasificar y luego extirpar para que el sistema político funcionase como hasta antes de su llegada, con sus inconsistencias, sus desigualdades y su parsimoniosa pasividad que impide pensar en posibilidades diferentes de vivir la cotidianidad y el mundo mismo.

Por esta razón, pensar al guerrillero o al disidente como un elemento éxtimo propone dos cosas fundamentales que se opondrían en definitiva a los reduccionismos de interpretación psicológica. La primera plantearía que el guerrillero no sólo practica y vive la disidencia sino que es parte sustancial del sistema simbólico de la cultura y del semblante del Estado. Es su esencia opositora pero también su distancia, lo que le nutre su orden y su ulterior juicio deslegitimador. Y, por otro lado, el guerrillero como éxtimo es también el lugar de deposito de goce de todos aquellos que le perciben como diferente, como anormal, como contrario a las ideas nacionales legítimas

20 J. Horgan, Psicología del terrorismo, Barcelona, Gedisa, 2006.

${ }^{21}$ H. M. Trujillo, J. González-Cabrera, C. León, C. Valenzuela y M. Moyano, "De la agresividad a la violencia terrorista: historia de una patología psicosocial previsible", en Psicología Conductual 14-2, 2006.

22 M. Crenshaw, "The subjective reality of the terrorist: ideological and psychological factors in terrorism", en R. O. Slater y M. Stohl, Current perspectives on international terrorism, London, McMillan Press, 1988, pp. 1246. 
que sustentan un odio hacia lo extranjero disidente, un separatismo avasallador, un aislamiento y una segregación, la mayor de las veces, clasista y xenófoba.

Para analizar las supuestas condiciones psicosociológicas del guerrillero, proponemos pensar también que en él mismo se manifiesta ya un registro de lo imaginario en su interpretación que es sostenido por las efectivas y constitutivas lógicas del Estado y sus mecanismos de coerción auspiciados por las técnicas psicológicas de clasificación. En su reverso, la extimidad propicia descifrar las posiciones políticas para dar lugar a la aleatoriedad de la lucha subversiva del guerrillero desde un punto que confronta la estabilidad del sistema simbólico de la cultura y la emergencia del guerrillero que representa un punto de encrucijada entre el goce como factor político y la presentación irreductible de la contingencia a nivel de lo real.

En efecto, la construcción y reconstrucción incesante del adversario político por parte del Estado se establece mediante los designios de un imaginario sobre el otro a partir del goce que deviene ordenador de las dinámicas propias de la coerción de Estado que se sostienen en el mismo imaginario que incentiva la enemistad que produce el Otro a través de los sujetos. De suerte que el sistema simbólico se ve orillado a reestablecerse mediante las mismas acciones de los sujetos contenidos y sostenidos mediante el registro imaginario y sus concepciones de estabilidad, progreso y desarrollo del Estado.

Como ya hemos revisado, el ejercicio psicologizante sobre el guerrillero es bastante común en algunos trabajos de psicología social que pretenden dar cuenta de su condición y opresión social y del uso del terror como estrategia política mas que darle un lugar como radicalización política. Pero, más allá de esto, es importante señalar que cuando se disponen características psicológicas a un disidente no se le extrapola del sistema simbólico sino que se le sostiene con una delimitación discursiva e imaginaria de su identidad política. Esto es posible cuando, al interior del discurso, se establecen directrices hegemónicas que legitiman e incluso validan la categorización sobre los guerrilleros. La relación guerrillero-adversario es, en sí misma, exterioridad.

Siguiendo lo señalado por Laclau y Mouffe, para hablar de la condición disidente y de la radicalidad puede pensarse en términos de "contingencia pura" al situar la "relación" política como "exterior"23. En otras palabras, al intentar suturar y llenar la identidad del guerrillero de características específicas, el orden simbólico a través de lo imaginario, predispone la relación externa que ha sido disfrazada de interioridad psicologizada para constreñir al adversario político y así poder justificar en un sujeto unitario la responsabilidad política de la subversión.

\section{El guerrillero como mito}

Ahora bien, hemos puntualizado que el guerrillero y su identidad política se sostienen en una exterioridad que puede llegar a mostrarse como íntima y es categorizada así por la ciencia psicológica desde la constante clasificación. Esta suerte de intercambio simbólico y supuestamente relacional es interiorizado de forma imaginaria y como tal sostiene fantasmagóricamente un conglomerado de definiciones y condiciones

23 E. Laclau, y C. Mouffe. Hegemonía y estrategia socialista. Hacia una radicalización de la democracia, Buenos Aires, Fondo de Cultura Económica, 2011, p. 82. 
que se disponen sobre la identidad política subversiva. A la identidad guerrillera se le dota de elementos que tienen, indiscutiblemente, una función social positiva e imaginaria. Ya sea depositarios de un ideal social o como elementos que permiten consignarle como disidente y entonces enjuiciarlo y deslegitimar su lucha política.

Lo anterior nos convoca a repasar la construcción del guerrillero como mito. Siguiendo los planteamientos del semiólogo francés Roland Barthes, "el mito no puede definirse ni por su objeto ni por su materia, puesto que cualquier materia puede ser dotada de significación"; todo "material mítico" plantea una "conciencia significante que puede razonar sobre ellos independientemente de su materia" 24 . El mito, al igual que cualquier acto del habla se sostiene pues en la fuerza de sus significantes y en el peso que éstos obtienen en la organización encadenada de los mismos. La cuestión trascendental aquí se plasma en la función mítica de la existencia de un guerrillero como agente contrario a un sistema de significaciones como el Estado y el orden social.

Siguiendo al mismo Barthes, "el significante en el mito" puede ser concebido desde dos ópticas, la primera como "término final del sistema lingüístico" o como "término inicial del sistema mítico" 25 . De suerte que el mito es la clausura de una identidad política como la del guerrillero pero, en sí mismo, el comienzo de un sistema mítico de significaciones que harán cada vez más indestructible la identidad mítica del guerrillero. El idealismo psicológico, en este sentido, no hace sino reforzar aún más la condición mítica de la identidad guerrillera pues dota de significación, cada vez más específica, el actuar del sujeto disidente.

Existe algo más, para Barthes, "el sentido" del cual está cargada la cadena significante del mito, "postula un saber, un pasado, una memoria, un orden comparativo de hechos, de ideas, de decisiones" y es precisamente aquí donde, al "devenir forma, el sentido aleja su contingencia, se evapora" ${ }^{26}$. Con lo anterior, las prácticas psicológicas, al desarrollar un saber sobre el guerrillero y su actuar como terrorista y otras atrocidades, no hacen sino fortalecer el mito y con esto mitigar la contingencia de todo el actuar subversivo del guerrillero. Lacan, basándose en Levi-Strauss, sabía muy bien que el mito, para tener las "propiedades de mito" no "explica nada" sino sólo refiere a una "organización significante" que demuestra las "antinomias de ciertas relaciones psíquicas"27.

Esto nos lleva a reconocer que la ubicación y especificación sobre el comportamiento o la conducta del guerrillero no hacen sino limitar su potencialidad acontecimental transformadora al fortalecer un saber ideologizado e imaginario sobre el disidente. En este sentido, las prácticas científicamente psicológicas que pretenden entender el porqué de la conducta de los terroristas únicamente fortalecen las ideas psicológicas hegemónicas que aíslan cada vez más a quienes se oponen a un determinado orden de Estado y a una realidad concreta. Como mencionan Lloyd Roberts \& Ror Malone, "el sujeto no es tan sólo representado en el lenguaje sino -más fundamentalmente- estructurado temporalmente a través del lenguaje" lo que hace suponer, en su temporalidad, "fisuras discursivas como reveladoras de un suje-

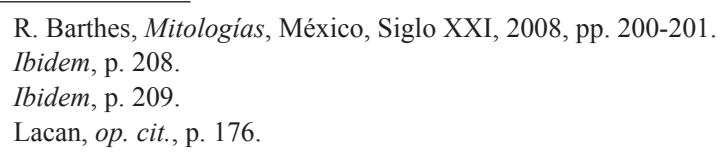


to traumático de enunciación difásica" 28 . Son esas mismas representaciones las que facilitan una difusión de la imagen del terrorista y su interpretación sin contar, de antemano, con que eso meramente especular desvela la organización clasificadora del sujeto disidente en torno a una identidad política completa.

Para ser capturado el guerrillero por el registro imaginario de forma pretendidamente universal y, subsecuentemente, al representarse mediante el universo simbólico, éste no deja de mostrar su exterioridad discursiva. Por más intentos o repertorios interpretativos de su conducta que se realicen sobre el guerrillero, lo que persiste insistentemente es el "movimiento estructural real" que se "impone" al "valor discursivo simbólico" pues éste corre el riesgo de "convertirse en un significado psicológico imaginario" que conceptualice y sostenga las ideas sobre la conducta anormal del guerrillero $^{29}$. Es este movimiento real estructural el que impide toda determinación simbólica por más significados que se le otorguen a la mítica forma del guerrillero pues se subvierte la simple imagen en la que son conceptualizados los disidentes, es el vínculo simbólico el que se contrapone a la cuadratura de la representación imaginaria del mito.

En este sentido, cuando señalamos que el guerrillero es presentado como mito no hacemos sino mostrar la imposibilidad conclusiva de la mitificación del disidente que puede llegar a ser presentada por la psicología social; pues, en todo discurso y en toda clasificación estructural, como refiere Jorge Alemán, hay una "respuesta a la imposibilidad y un resto heterogéneo, denominado por Lacan objeto a, que muestra que la realidad no puede ser totalmente simbolizada por la vía del significante" ${ }^{30}$. De esta manera, el soporte real, como residuo heterogéneo, sería la porción del significante que se rehúsa a ser capturada por el sentido y por la significación del sistema simbólico y por la cual el mito sólo es representado y muestra su fracaso en la simbolización.

Si la apuesta psicosocial se divide entre interpretar las conductas sociales de los sujetos o definir su subjetividad presuntamente colectiva, es necesario señalar que al cuestionar estas dos líneas interpretativas. Pues esto no se hace sino reforzar los diques simbólicos que delimitan el suspenso del orden discursivo simbólico que es provocado por la aleatoriedad del guerrillero. Se captura, con esto, lo que Pavón-Cuéllar refiere como lo "real subversivo" que es "reabsorbido" por la insistencia del Otro mediante el "sistema simbólico de la cultura" 31 . Si el guerrillero puede ser edificado como mito por aquellos quienes pretenden analizarlo psicológicamente, es precisamente porque en su simbolización queda representada la fuerza del sistema simbólico para detener la aleatoriedad y la contingencia de la identidad política. Es ahí donde toda práctica psicológica ideologizada que determina al subversivo se convierte en sirviente de ese sistema simbólico que todo lo organiza y distribuye. El acto real del cuerpo del guerrillero es limitado mientras más se busque interpretar su figura mítica y en cuanto más sea limitado por las directrices psicosociológicas.

Por último, siguiendo nuevamente a Barthes, podemos comprender que los "conceptos míticos", como el del guerrillero, son "llenados" por determinaciones signi-

28 J. Lloyd Roberts, y K. Ror Malone, "La subjetividad en el análisis lacaniano de discurso: el trauma y el discurso político”, en I. Parker y D. Pavón-Cuéllar, Lacan, discurso, acontecimiento. Nuevos análisis de la indeterminación textual, México, Plaza y Valdés-UMSNH, 2013, pp. 301-316, aquí p. 302.

29 D. Pavón-Cuéllar, From the conscious interior to an exterior unconscious, London, Karnac, 2010, p. 36.

30 J. Alemán, En la frontera. Sujeto y capitalismo, Barcelona Gedisa, 2014, p. 32.

31 D. Pavón-Cuéllar, Elementos políticos de marxismo lacaniano, México, Paradiso, 2014, p. 71. 
ficantes que les dotan de sentido pero que, a su vez, no presentan "ninguna fijeza" y por tanto "pueden hacerse, alterarse, deshacerse o desaparecer completamente" 32 . De esta manera, mientras más se dote de interpretación simbólica el saber sobre el mito del guerrillero se seguirá sosteniendo la dinámica de éste. De suerte que se puede condenar al acto subversivo a una interpretación limitativa que no transforma la verdad del sistema simbólico sino sólo la adecua para seguir perpetuándola.

\section{Conclusiones}

Para finalizar debemos precisar que la extimidad, constitutiva de las relaciones sociales y políticas, permite explorar los terrenos en que lo exterior organiza las conceptualizaciones internas de los sujetos. Las prácticas de sobredeterminación ideológica interior que se añaden al guerrillero buscando interpretar su realidad no hacen sino desvelar la traumática violencia con la que el Estado opera y clasifica a los disidentes más allá del ejercicio de la fuerza de Estado. Para quedar organizado el entramado discursivo sobre la actividad guerrillera no sólo se busca aniquilar la materialidad corporal real del guerrillero sino intentar dejar un rastro de su aniquilamiento en el sistema simbólico que organiza la vida contemporánea.

Si se busca analizar psicológicamente al adversario y si se busca determinar su personalidad y su conducta, se evidencia la incesante complicidad de la psicología por determinar la anormalidad y no sólo se mitiga la posibilidad contingente del actuar subversivo sino que se solidifican aún más los muelles que determinan las condiciones óptimas en las que el sistema de Estado puede reproducirse y perpetuarse. En este sentido, al abrir la contingencia del guerrillero explorando su constitutiva identidad política podemos también discernir en la verdad operativa del sistema de Estado y los medios que éste utiliza para contener y determinar a sus enemigos. De esta manera, la psicología coadyuva a la mitificación del guerrillero y permite una mejor clasificación para poder servir como mecanismo coercitivo de grupos subversivos posteriores.

Finalmente, el desconocido y amenazante hielo que tocara el hijo del Coronel Aureliano Buendía, no será más que un paradigma azaroso que reorganiza la anquilosada vida política. Y así, con vicisitudes, manifestar: ¡Hasta la victoria siempre! Con todo y los lastres que hemos enunciado pues, como sabemos. Si la extimidad resulta paradójicamente externa, algo de la realidad concreta y exterior puede ser cambiada radicalmente por aquellos quienes practican la disidencia, evitando ser seccionada por quienes, un paso antes de la realidad histórica, hacemos psicología social comprometida.

32 Barthes, op. cit., p. 212. 